Article

\title{
Assessment of Trichogramma japonicum and T. chilonis as Potential Biological Control Agents of Yellow Stem Borer in Rice
}

\author{
Rui Tang ${ }^{1}$, Dirk Babendreier ${ }^{1,2, *}$, Feng Zhang ${ }^{1}$, Min Kang ${ }^{3}$, Kai Song ${ }^{4}$ and Mao-Lin Hou ${ }^{5, *}$ \\ 1 MoA-CABI Joint Laboratory for Bio-Safety, Institute of Plant Protection, Chinese Academy of Agricultural \\ Sciences, 2 West Yuan-Ming-Yuan Road, Haidian District, Beijing 100193, China; r.tang@cabi.org (R.T.); \\ f.zhang@cabi.org (F.Z.) \\ 2 CABI Europe-Switzerland, Rue des Grillons 1, Delémont CH-2800, Switzerland \\ 3 Plant Protection and Quarantine Station, Dehong Prefecture Agriculture Bureau, Dehong 678400, China; \\ kangmin318@sina.com \\ 4 Dryland Farming Institute, Hebei Academy of Agricultural and Forestry Sciences, Hengshui 053000, China; \\ hs_kai@126.com \\ 5 State Key Laboratory for Biology of Plant Disease and Insect Pests, Institute of Plant Protection, \\ Chinese Academy of Agricultural Sciences, Beijing 100193, China \\ * Correspondence: d.babendreier@cabi.org (D.B.); mlhou@ippcaas.cn (M.-L.H.)
}

Academic Editors: Andrew G. S. Cuthbertson and Eric W. Riddick

Received: 24 December 2016; Accepted: 24 January 2017; Published: 8 February 2017

\begin{abstract}
Two species of Trichogramma wasps were assessed for their effectiveness against yellow stem borer Scirpophaga incertulas. A laboratory cage test with T. japonicum and T. chilonis showed that both species parasitized yellow stem borer egg masses at $60.0 \% \pm 9.13 \%$ and $40.7 \% \pm 7.11 \%$, respectively, with egg parasitism rates of $15.8 \% \pm 22.2 \%$ for $T$. japonicum and $2.8 \% \pm 5.0 \%$ for $T$. chilonis. Once the host eggs were parasitized, emergence rates were high for both species $(95.7 \% \pm 0.12 \%$ for T. japonicum and $100 \%$ for T. chilonis). In paddy field trials, the two Trichogramma species were released at three densities (50,000/ha, 100,000/ha and 200,000/ha) in Southwestern China. Egg mass parasitism was $9 \% \pm 7.7 \%$ for $T$. japonicum and $15 \% \pm 14.1 \%$ for T. chilonis, and again only a relatively small fraction of eggs was successfully parasitized. No clear conclusion could be drawn on the most efficient release rate as no significant differences were found among the three release rates. A comparison of field-collected T. japonicum with T. japonicum and T. chilonis mass reared on Corcyra cephalonica showed significantly larger body size and ovipositor length in field-collected wasps, suggesting potentially higher effectiveness on yellow stem borer eggs after at least one generation on the target host. Factors contributing to the low field parasitism rates are discussed.
\end{abstract}

Keywords: Trichogramma; yellow stem borer; parasitism rate; field release

\section{Introduction}

Rice (Oryza sativa L.) is the most important crop in the world [1] and plays a central part in Asian food security [2]. This crop is widely distributed especially in Southern parts of China [3] where rice accounts for $88.7 \%$ of the total agricultural acreage [3]. Yunnan Province is located in the Southwest of China, and is considered to be part of the Greater Mekong Subregion, together with Myanmar, Laos, Cambodia, Vietnam and Thailand [4]. Rice covers over half of the cropping lands in this region [5] and is considered to be the most important crop there [5,6]. However, rice production in this area is suffering from serious pest and disease damage [7-10] causing substantial yield losses every year [6,11-13]. 
Key pests of rice include striped stem borer (Chilo suppressalis Walker, Crambidae) [6], yellow stem borer (YSB) (Scirpophaga incertulas Walker, Crambidae) [13], pink borer (Sesamia inferens Walker, Noctuidae) [14], rice leaf folder (Cnaphalocrocis medinalis Guenée, Crambidae) [13], rice plant hopper (Nilaparvata lugens Stål, Delphacidae) [15] and rice green semilooper (Naranga aenescens Moore, Noctuidae) [16]. Among those, the yellow stem borer is considered to be the most important pest of rain-fed low land and flood-prone rice ecosystems [17]. Populations of this pest substantially increased within one decade recently in paddy fields in Yunnan Province along with continuous promotion of double cropped rice in this area [18].

Conventional control methods for Lepidoptera pests in paddy fields usually involve the application of agrochemicals [5]. However, these methods may cause damage to the environment and lead to food safety issues, particularly because broad-spectrum insecticides of considerable toxicity are generally used [19]. Optimized methods with less environmental impact and high sustainability are in demand, such as releasing biological control agents [11]. So far, many studies have demonstrated that Trichogramma wasps can successfully control Lepidopteran pests by parasitizing their eggs [6,11,20-22]. Major success stories have been reported from maize crops and Trichogramma has been introduced in many maize growing areas worldwide [20]. In rice, Trichogramma has been studied for management of key Lepidopteran pests, however, despite promising results, Trichogramma is not yet used commercially in paddy fields. Recent findings from China indicate that Trichogramma releases may be considered practical for control of striped stem borer and rice leaf folder $[6,21,22]$. However, it is less clear whether the yellow stem borer can also be controlled by Trichogramma wasps as less work has been done on this species so far [23]. Furthermore, yellow stem borer egg masses consist of several layers of eggs and are protected by a cover of hairs [17]. These protection mechanisms could lead to difficulties for Trichogramma females to reach the eggs, especially the lower egg layers; a problem potentially linked to body size and ovipositor length of the wasps. From field surveys conducted in Indian rice fields, there are hints indicating that yellow stem borer eggs may not be effectively parasitized under natural conditions $[24,25]$. On the other hand, more positive results have been reported from a field survey in China showing rather high parasitism rates of yellow stem borer eggs in the range of $46.7 \%$ to $79.1 \%$ [26,27]. In general, there have been very few attempts to control yellow stem borers by inundative releases of Trichogramma, and none have occurred in China. However, one such experiment achieved a yield increase of $12 \%$ at maximum compared to the untreated control in paddy fields when releasing 200,000 T. japonicum adults/ha in two or four split applications [28]. Our aim was to assess the performance of two different Trichogramma species in both field cage and field release tests in order to explore their potential as biological control agents of yellow stem borer.

\section{Materials and Methods}

\subsection{Insects and Plants}

T. chilonis (Ishii) was collected from striped stem borer eggs in Cuijia Township ( $25^{\circ} 55^{\prime} 46^{\prime \prime} \mathrm{N}$, 109 $37^{\prime} 51^{\prime \prime}$ E), Xing'an County, Guangxi Province, China during June 2011, and T. japonicum Ashmead was collected from yellow stem borer eggs in Husa Township ( $\left.24^{\circ} 27^{\prime} 48^{\prime \prime} \mathrm{N}, 97^{\circ} 53^{\prime} 24^{\prime \prime} \mathrm{E}\right)$, Dehong Prefecture, Yunnan Province, China during July 2012. Both species were reared at Tianyi Biological Control Company Inc., Hengshui, Hebei Province, China, on Sitotroga cerealella Olivier with regular rejuvenation provided (host eggs were altered every 15 generations between Sitotroga and Corcyra cephalonica Stainton and backcrossing was conducted annually using field-collected wasps) (Appendix A Table A1). For field experiments conducted in July and August of 2013 in Husa Township, tricho-cards with approximately 500 wasps emerging per card were used. The tricho-cards are of a folded design for protection from rain, sunshine, and natural enemies, with parasitized substitute host eggs glued on the inner side and a hole on one end for hanging on rice leaves. The tricho-cards were delivered several times to the experiment site so as to coincide with the field release timing. 
Yellow stem borer moths were collected from nearby rice fields by sweep nets and then caged for oviposition on rice plants. Egg masses were collected daily from the plants and used within $24 \mathrm{~h}$ in the tests. Rice plants at heading stage randomly selected from the paddy fields near the experimental site were transplanted together with soil to pots and used for YSB oviposition and in cage tests.

\subsection{Performance of the Trichogramma Species on Substitute Host}

A test was conducted to measure the performance of both wasp species on the substitute host S. cerealella. Five hundred fresh, UV-sterilized Sitotroga eggs were each exposed to 100 T. japonicum and T. chilonis wasps in a Petri dish. After $48 \mathrm{~h}$, the wasps were removed and the eggs were transferred to a Petri dish lined with moistened filter paper under room temperature. The emerged Trichogramma adults were counted and sexed daily. The measurement was replicated three times for each species.

\subsection{Cage Tests for Parasitism}

Cage tests were conducted to assess the capacity of T. japonicum and T. chilonis to parasitize YSB eggs. Rice hills at early heading stage were collected from the field and grown in pots in cylindrical cages (120 cm in height and $35 \mathrm{~cm}$ in diameter) made of wire and fine netting at natural conditions (1 to 2 hills per cage). Twenty pairs of yellow stem borer adults were introduced into a cage for oviposition. After $24 \mathrm{~h}, 1 / 5$ of a tricho-card of either T. japonicum or T. chilonis that was ready to emerge was introduced per cage, corresponding to an estimated 100 parasitized eggs for each of the two species tested. Four replicates (cages) were set up for each Trichogramma species. Forty-eight hours after introduction of tricho-cards, all YSB egg masses were cut down together with rice leaves and placed individually on a moistened filter paper in glass tubes $(15 \mathrm{~cm}$ in length and $2.5 \mathrm{~cm}$ in diameter) under room temperature. The egg masses were observed daily for hatching of yellow stem borer larvae, if any (and hatched larvae were removed), or emergence of Trichogramma wasps. Number of hatched larvae and emerged wasps were recorded. The emerged wasps were sorted by sex. Number of dead unparasitized eggs and dead parasitized eggs were differentiated by dissection under a stereo microscope after wasp emergence had ceased for three days. Egg mass parasitism rate was calculated by dividing numbers of parasitized egg masses with total numbers of egg masses. Egg parasitism rate was calculated by dividing numbers of parasitized eggs with total numbers of eggs.

\subsection{Field Tests for Parasitism}

Field performance of the two Trichogramma species was tested by releasing the wasps in paddy fields. The fields were planted to conventional rice varieties of "Deyou 8", "Deyou 12" and "Deyou 16" that were at heading to milking stage when the experiments were conducted. Insecticides were not applied for one week before releasing of Trichogramma and during the experiment period.

Both T. japonicum and T. chilonis were released at 100 points per ha at 500, 1000 and 2000 wasps per point, corresponding to release densities of 50,000, 100,000 and 200,000 wasps/ha, respectively. For each combination of release density and Trichogramma species, there were four replicates (field plots). Another four plots were used as control. Each plot covered an area of $900 \mathrm{~m}^{2}(30 \mathrm{~m} \times 30 \mathrm{~m})$, and was at least $15 \mathrm{~m}$ (edge to edge) away from the neighboring plots. Tricho-cards were released in a plot at nine points that were $10 \mathrm{~m}$ apart from each other. The plots were randomly assigned to treatments in the field (Appendix A Figure A1).

On the same day when the blackened (ready-to-emerge) tricho-cards were released, sentinel YSB egg masses less than $24 \mathrm{~h}$ old were placed in the plots. The sentinel egg masses were obtained from the established cage rearing. For each plot, 10 YSB egg masses together with a rice leaf segment were randomly fixed on either leaf side by a stapler. Forty-eight hours after releasing, YSB egg masses were recollected from the fields and taken back to laboratory. In addition to re-collecting the actively placed egg masses, all other YSB egg masses found were also taken back to the lab. Egg masses were kept under natural conditions and observed for number of hatched larvae, emerged wasps and dead eggs, as described in the cage tests. The local weather in July and August of 2013 was characterized by small 
rains occurring at least once a day, with a temperature range of $22{ }^{\circ} \mathrm{C}$ to $33{ }^{\circ} \mathrm{C}$ and an average wind speed less than $3.4 \mathrm{~m} / \mathrm{s}$.

\subsection{Morphological Observations}

Morphological parameters potentially affecting the ability to parasitize YSB eggs were measured for field-collected and mass reared Trichogramma. The field-collected T. japonicum were from YSB egg masses collected in 2014 from paddy fields in Husa Township where T. japonicum had been released for one year. The mass reared T. japonicum and T. chilonis were produced by the local Trichogramma rearing facility in Mangshi, Dehong Prefecture, where the wasps had been reared for $>20$ generations on eggs of C. cephalonica. Body length, ovipositor length and hind tibia length were measured under a stereo microscope to 15 wasps for each of the field-collected T. japonicum and the mass reared T. japonicum and T. chilonis.

\subsection{Data Analysis}

Egg parasitism rate was calculated as: (number of dead parasitized eggs + number of emerged wasps)/(total number of eggs); egg mass parasitism rate, as number of parasitized egg masses/total number of egg masses; and emergence rate, as number of emerged wasps/(number of dead parasitized eggs + number of emerged wasps). For the field test, mean values of the parameters were calculated for a plot and then tested with a two-factorial ANOVA for the two factors "species" and "densities". For the cage test, means of the parameters between the two species were differentiated by $t$-test or Mann-Whitney $U$-test. All proportional data were arcsin-squareroot transformed before analyses, which were performed with the program IBM SPSS Statistics 19.0.0 (SPSS Inc., Chicago, IL, USA).

\section{Results}

\subsection{Performance of the Trichogramma Species on Substitute Host}

Ninety percent of the Sitotroga eggs were parasitized in the test. From a total of 500 eggs exposed for each of the two Trichogramma species, there were $289 \pm 46$ T. japonicum wasps and $245 \pm 18$ T. chilonis wasps that emerged, respectively. No significant difference was found in mean emergence rates between T. japonicum $(64.2 \% \pm 10.2 \%)$ and T. chilonis $(54.4 \% \pm 4 \% ; t=0.902, p=0.42)$.

\subsection{Cage Tests}

A total of 77 YSB egg masses were collected from the cage tests, 37 for the $T$. chilonis treatment and 40 for the T. japonicum treatment. Mean parasitism rates of egg masses were $60.0 \% \pm 9.1 \%$ for T. japonicum and $40.7 \% \pm 7.1 \%$ for $T$. chilonis and did not significantly differ from each other $\left(t_{6}=1.67\right.$, $p=0.145 ;$ Figure 1a).

In contrast, $T$. japonicum wasps showed a significantly higher parasitism rate on yellow stem borer eggs $(15.8 \% \pm 22.2 \%)$ than $T$. chilonis $\left(2.8 \% \pm 5.0 \%, t_{6}=3.51, p=0.0011\right.$; Figure $\left.1 \mathrm{~b}\right)$. The parasitism rate altogether was rather low for both species. There were an average of $1.73 \pm 2.04$ T. japonicum wasps and $0.65 \pm 0.98 \mathrm{~T}$. chilonis wasps emerging from an egg mass. Overall emergence rate for T. japonicum was $94.5 \%$, which was not significantly different from that of T. chilonis (100\%; Mann-Whitney $U$ test, $U=157.5, p=0.521$, Figure $1 c$ ). Sex ratios (measured as proportion of females) were $71.2 \%$ for T. japonicum and $62.5 \%$ for T. chilonis, with no difference observed between the two species $\left(t_{6}=0.703, p=0.486\right.$, Figure $\left.1 \mathrm{~d}\right)$. 


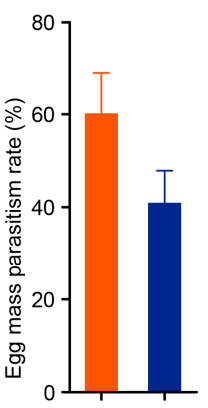

a

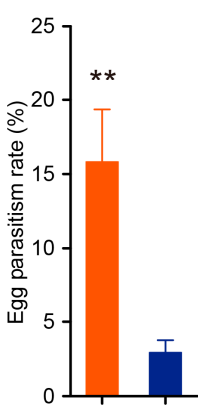

b

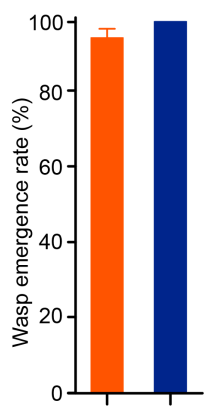

C

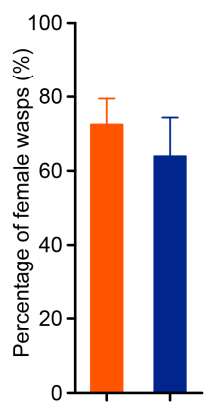

d

Figure 1. Parameters indicating performances of T. japonicum and T. chilonis in the cage test. Bar charts show comparisons of (a) egg mass parasitism rate; (b) egg parasitism rate; (c) emergence rate; and (d) proportion of females, between the two Trichogramma species. Error bars indicate + standard error (SE) and asterisks indicate significant difference observed at $p<0.01$.

\subsection{Field Tests}

In total, 370 YSB egg masses were recollected from the 28 plots of which 280 were sentinel egg masses and 90 were naturally laid. This included 43 egg masses from control plots, 165 from T. japonicum released plots and 162 from T. chilonis released plots. Because no significant difference was observed between sentinel eggs and naturally laid eggs in egg parasitism rates (Appendix A Figure A2), data from all egg masses were pooled for further analysis. For the 43 egg masses collected from control plots, no attack by Trichogramma was observed, resulting in zero parasitism rate. In the Trichogramma release plots, parasitism rates of YSB egg masses were $9.0 \% \pm 7.6 \%$ and $15.1 \% \pm 14.1 \%$ for T. japonicum and T. chilonis, respectively. Rather low parasitism rates of YSB eggs were found in the present study with $0.35 \% \pm 0.36 \%$ and $0.68 \% \pm 0.66 \%$ for $T$. japonicum and T. chilonis, respectively. No significant differences were observed between the two Trichogramma species, neither for egg mass parasitism rate (excluding the control plots showing zero parasitism, ANOVA, $F_{1,18}=0.84, p=0.37$ ) or for egg parasitism rate $\left(F_{1,18}=1.20, p=0.29\right.$, Figure 2$)$. The emergence rates were $84.4 \% \pm 19 \%$ for T. japonicum and $83.4 \% \pm 15 \%$ for $T$. chilonis $\left(F_{1,18}=1.7, p=0.2\right)$. Furthermore, no significant differences were found among the three release densities tested, neither for egg mass parasitism $\left(F_{2,18}=0.42\right.$; $p=0.66)$ nor for egg parasitism $\left(F_{2,18}=1.70 p=0.21\right.$, Figure 2$)$. A significant interaction effect was observed between wasp species and release density for egg mass parasitism rate $\left(F_{2,18}=4.14\right.$, $p=0.033)$ but not just for egg parasitism rate $\left(F_{2,18}=3.21, p=0.064\right)$. For cage tests, a weak but significant negative correlation was found between egg mass size (indicated by total egg number of single egg mass) and egg parasitism rate (Appendix A Figure A3, Pearson correlation: $R^{2}=-0.349$, $p=0.002$ ). Yet no significant correlation could be observed between egg mass size and egg parasitism rate in field tests (Pearson correlation: $R^{2}=-0.149, p=0.451$ ). 
Rate (\%)
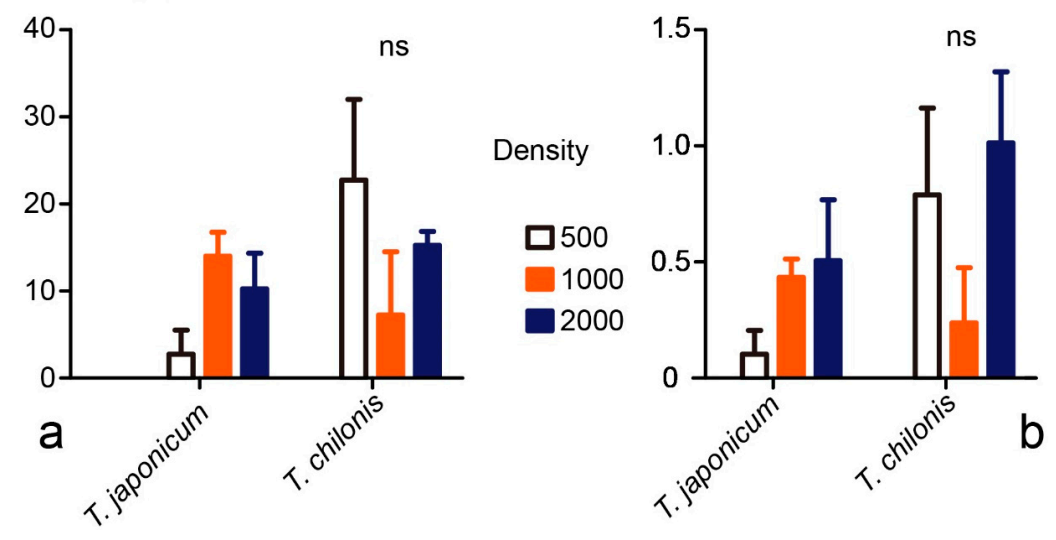

Figure 2. Results from field experiment to assess yellow stem borer (YSB) parasitism rates of two Trichogramma species at three release densities (500, 1000 or 2000 wasps per release point, $n=4$ for each treatment). Error bars indicate + SE. (a) YSB egg mass parasitism rate; (b) YSB egg parasitism rate.

\subsection{Morphological Comparison}

The field-collected Trichogramma wasps were identified as T. japonicum (Appendix A Figure A4). Significant differences between field-collected T. japonicum and mass reared T. japonicum or T. chilonis were found for body length (ANOVA, $\left.F_{2,36}=93.5, p<0.001\right)$, ovipositor length $\left(F_{2,36}=51.4, p<0.001\right)$ and hind tibia length $\left(F_{2,36}=5.88, p=0.0062\right.$, Figure 3$)$. In particular, the field-collected $T$. japonicum were larger than the mass reared conspecifics (Tukey HSD test, body length: $p<0.001$, ovipositor length: $p<0.001)$, although no significant difference was found for hind tibia length $(p=0.134)$. Furthermore, the mass reared T. japonicum were larger than the mass reared T. chilonis for two tested parameters (body length: $p<0.001$, ovipositor length: $p<0.001$, hind tibia length: $p=0.242$ )

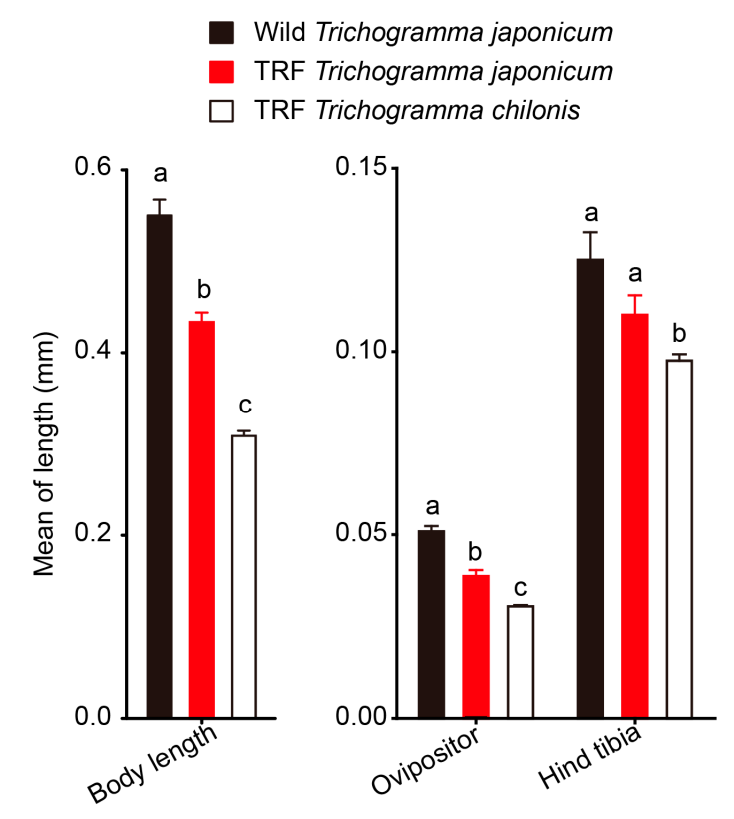

Figure 3. Comparison of body length, ovipositor length and hind tibia length among Trchogramma species/strains either collected from yellow stem borer egg masses from paddy fields (wild T. japonicum) or reared in Trichogramma rearing facilities (TRFs) on eggs of C. cephalonica $(n=15)$. Error bars indicate + SE. Lower case letters indicate significant differences among the three species/strains (one-way ANOVA followed by Tukey HSD multiple comparison). 


\section{Discussion}

In the present study, we tested two Trichogramma species collected in the target region for their potential as a biological control agent of YSB, the main pest of rice in the target region. No conclusion can be drawn as to which of the two tested species might be better, since results from cage and field tests were not consistent and slightly contradictory. Overall, parasitism rates obtained for T. japonicum and T. chilonis in both the cage and field tests were relatively low and raise concerns as to whether these species could be successfully applied. However, a number of reasons may have contributed to low egg mass parasitism rates in the field. First of all, it cannot be ruled out that the quality of the released material is impaired, which may be due to being mass produced for many generations on Sitotroga [26,29], or due to sub-optimal conditions during transportation of the tricho-cards from the production facility in Hengshui to the release site in Husa Township. The low emergence rates found in the substitute host tests on Sitotroga eggs in the present study provide some evidence that quality of the wasps used in the study here was below optimum. It is furthermore well known for field release studies with inundative releases in plots that dispersal from these plots can be an issue and this has also been shown for Trichogramma [30]. Even though the release area was a bit larger than the area from which measurements were taken, dispersal over 10-20 m can happen for Trichogramma with corresponding effects on parasitism. In addition, the experiment was run over a short time only to avoid too much loss of egg masses due to predation. It is also likely that not all Trichogramma emerged during the first day of the experiment, i.e., fewer Trichogramma wasps may have been active during the length of the experiment than would be anticipated from the release rate. Last but not least, Trichogramma wasps may have had difficulties to find egg masses because they were placed experimentally on leaves which may quickly dry in the field and thus become unattractive. In light of the above considerations and compared to other studies on similar scales, the relatively low parasitism rates may be partly explained; rates would perhaps be higher in larger scale releases. Also, the fact that this study demonstrated no consistent effect of the release density indicates that unknown factors may have played a role in this field experiment.

However, despite the fact that egg mass parasitism may have been underestimated in the present study, a particular concern is still the low parasitism rates that were found for eggs, i.e., even though an egg mass might have been parasitized, Trichogramma females only parasitized a small proportion of that egg mass. This may be related to the specific features of YSB egg masses which on one hand consist of several layers of eggs, and on the other hand are also covered with hairs provided by the YSB female moth. In general, few studies have been carried out to test Trichogramma wasps on yellow stem borers and in particular, field surveys have mostly only reported egg mass parasitism rates instead of egg parasitism rates for Trichogramma wasps toward YSB. For egg masses, exceptional rates of $100 \%$ parasitism could be reached for T. japonicum toward the first generation of YSB eggs in the fields [11]. In contrast, several surveys have reported that parasitism rates of YSB eggs by Trichogramma in paddy fields ranged only from $2.1 \%$ to $23.1 \%$ [31-33]. These rates are considerably lower than those generally found for striped stem borer eggs, where parasitism rates reach up to $85.8 \%$ [6,21].

Hairs of pests have been proved to be related to both direct [34] and indirect [35] protection from natural enemy attacks. Similarly, due to the special hair cover structure and layers of eggs inside, YSB eggs usually suffer less from egg parasitoid wasps [25]. This is supported by Lou et al. [11] who recently showed that the eggs from deeper layers of YSB egg masses usually escape from being parasitized by Trichogramma wasps. At the high densities used for the field cage study here (100 wasps per 10 egg masses), it may be concluded that wasps would parasitize all eggs they could possibly reach which would suggest about $21 \%$ for T. japonicum and $4 \%$ for $T$. chilonis on small egg masses and $4.7 \%$ for $\mathrm{T}$. japonicum and $1.9 \%$ for $\mathrm{T}$. chilonis on larger egg masses. In fact, a negative correlation of egg parasitism rates with egg mass size was observed in cage tests, which indicates that small egg masses were more likely to be parasitized in a higher proportion than large egg masses. No such correlation was found in the field test. We were not able in the present study to precisely analyse the rate of parasitization of eggs in the different layers of egg masses, and additional studies would be worthwhile 
to deepen our understanding on the factors underlying our findings. Even though the hairs on the egg surface are likely impairing parasitism rates, Trichogramma offspring may be expected to benefit from hairs of parasitized YSB egg masses [36] as predation risk is reduced compared to Trichogramma offspring inside striped stem borer or rice leaf folder eggs $[34,35]$ thus increasing offspring survival rate [37].

In the experimenta, no Trichogramma at all were found in the control fields or during additional collections in Husa Town [38]. Although the reasons for this remain unknown, it may be speculated that the high rate of recent pesticide applications is a contributing factor. Interestingly, Trichogramma wasps were recovered two months after the last of six releases that were conducted in 20 hectares of demonstration paddy fields located in Mangshi, Dehong, Yunnan Province, indicating that a natural T. japonicum population has successfully established there. It is known that body size of host parasitoid wasps can be determined by host egg sizes [39,40], and we found that field-collected T. japonicum strains were significantly larger than lab strains, produced on rather small eggs of the factitious host Sitotroga, and also had longer ovipositors. Larger body sizes of parasitoids are generally related to higher egg load, lifetime fecundity, ability to disperse, host locating ability, and thus may contribute to increased parasitism rates [39-41]. This suggests that Trichogramma wasps reared in small eggs might encounter difficulties when facing larger eggs or packs of egg masses, especially when they are covered with hairs in the field. In this case, second generation wasps emerging from field hosts may be more successful in parasitizing YSB eggs.

\section{Conclusions}

In conclusion, the overall low parasitism rates found in the present study suggest that the two Trichogramma species tested would not be highly successful for inundative biological control of YSB, in particular because of the low attack of eggs observed. However, considering the limitations of such an experimental study (see points discussed above) and likely higher success rates of larger wasps emerging from the field host, application of Trichogramma could have a positive effect on YSB pest control based on inundative or even inoculative releases in the longer term, and further studies will be needed to fully understand the potential, but also constraints, of the present system.

Acknowledgments: We thank Yang Mingxi and Yang Zhiyuan from Yunnan Agriculture University for assisting in our lab and field experiments. We thank the local Agriculture Extension Service Station in Husa for providing logistical support to our field work. This study received funds from EuropeAid GMS RICE IPM project (DCI-Food/2010/230-238) and China's donation to the CABI Development Fund.

Author Contributions: Mao-Lin Hou, Babendreier Dirk and Rui Tang designed the study. Rui Tang, Kai Song, Min Kang and Babendreier Dirk conducted the experiments. Rui Tang, Babendreier Dirk and Mao-Lin Hou analyzed the data. Rui Tang, Babendreier Dirk, Mao-Lin Hou and Feng Zhang developed the manuscript.

Conflicts of Interest: The authors declare no conflicts of interest.

\section{Appendix}

Table A1. Quality parameters of Trichogramma cards provided by TBCC *.

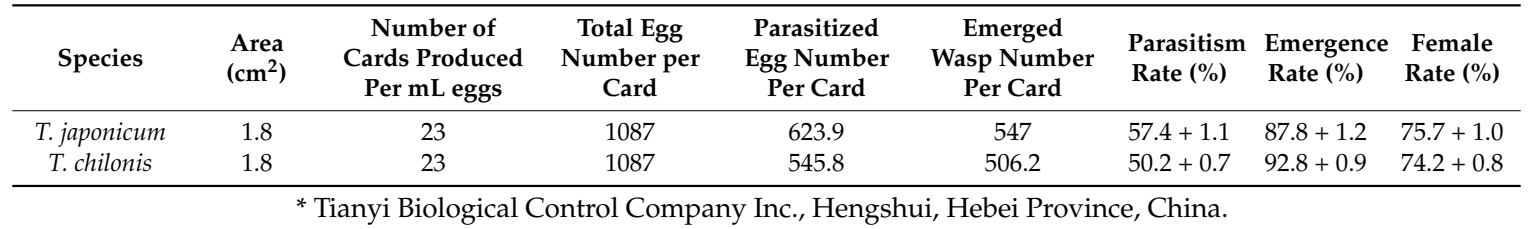




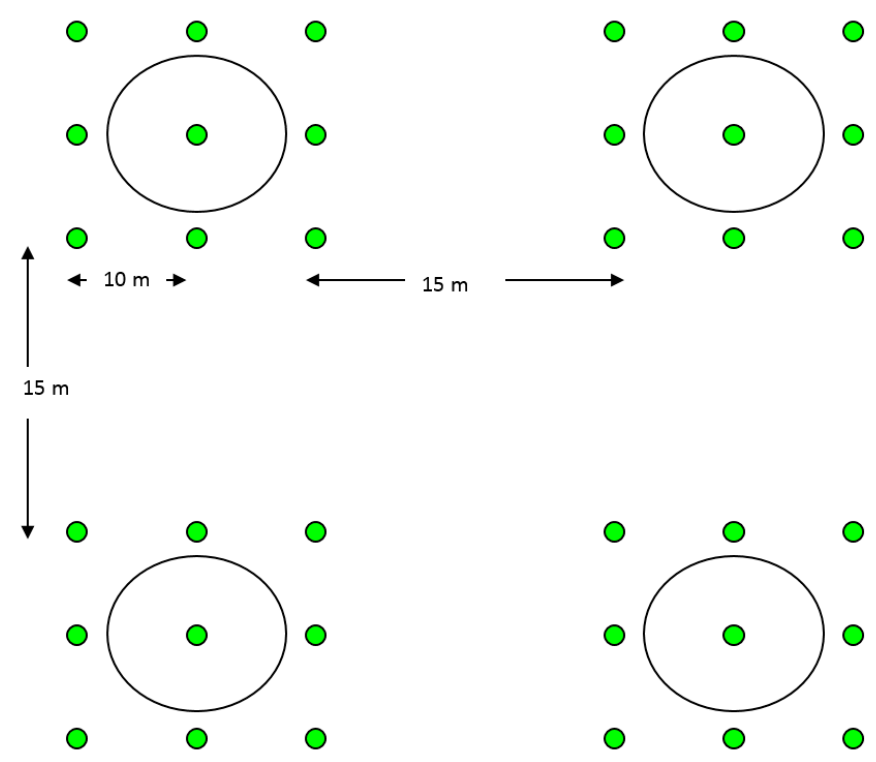

Figure A1. Design of field trial with Trichogramma wasps targeting yellow stem borer egg masses. Green circles indicate releasing points in each plot. A total of 28 plots were randomly chosen in the paddy field with at least $15 \mathrm{~m}$ distance from edge to edge. Two species of wasps were released in three densities of 500, 1000 and 2000 per releasing point respectively.

a

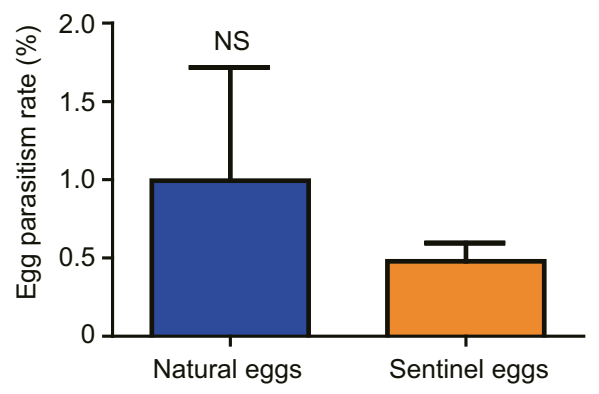

C

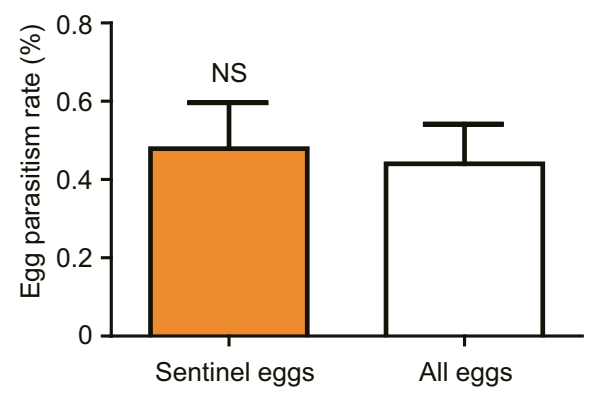

b

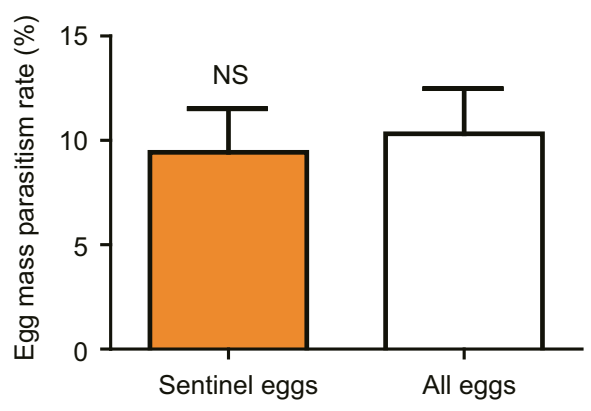

d

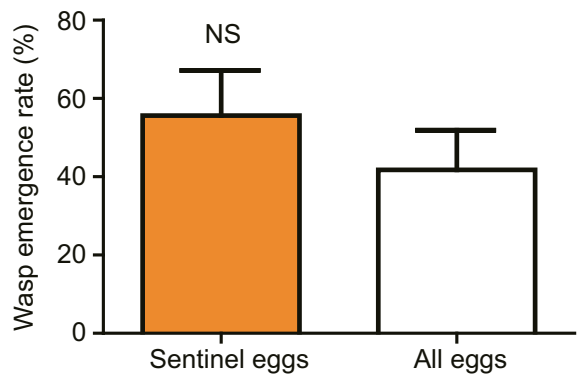

Figure A2. Comparison of data from sentinel and naturally laid YSB eggs. $t$-test, $n=28$, error bars indicate + SE. (a) Egg parasitism rate comparison between natural and sentinel eggs. $t=0.67, p=0.5$; (b) Egg mass parasitism rate comparison between sentinel and all eggs. $t=0.29, p=0.77$; (c) Egg parasitism rate comparison between sentinel and all eggs. $t=0.25, p=0.8$; (d) Wasp emergence rate comparison between sentinel and all eggs. $t_{33}=0.9, p=0.37$. 
a

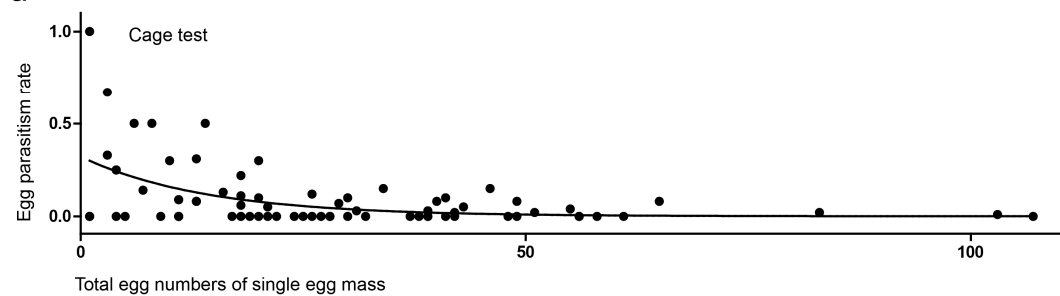

b

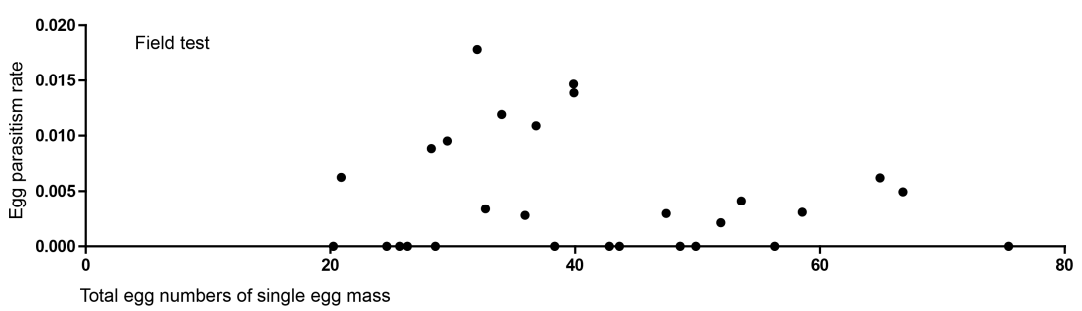

Figure A3. Non-linear regression between egg mass size and parasitism rate. (a) data from cage tests. Pearson correlation: $R^{2}=-0.349, p=0.002 ;(\mathbf{b})$ data from field tests. Pearson correlation: $R^{2}=-0.149$, $p=0.451$.

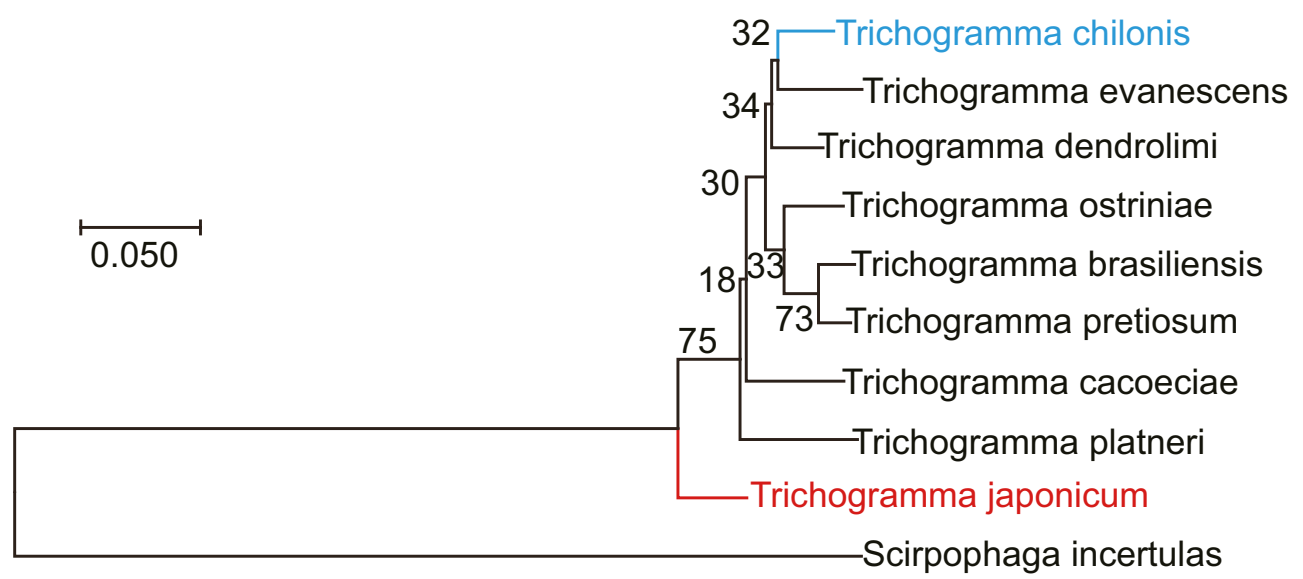

Figure A4. The Trichogramma evolutionary history was inferred using the Neighbor-Joining method [42]. The optimal tree with the sum of branch length $=0.94808551$ is shown. The percentage of replicate trees in which the associated taxa clustered together in the bootstrap test (1000 replicates) are shown next to the branches [43]. Scale indicates evolutionary distances among species. A total of nine Trichogramma species and yellow stem borer were picked up for phylogenetic analysis. Ten cytochrome oxidase subunit I genes were introduced from gene bank for the analysis including T. japonicum (gi | 727353589 |), T. chilonis (gi | 700682216 |), T. dendrolimi (gi | 449043448 |), T. ostriniae (gi |74483381 |), T. brasiliensis (gi |74483391 I), T. platneri (gi | 1052465561 I), T. pretiosum (gi |742527366 |), T. evanescens (gi |742527376 I), T. cacoeciae (gi |700676774 I), and Scirpophaga incertulas (gi |633259618 I). The tree is drawn to scale, with branch lengths in the same units as those of the evolutionary distances used to infer the phylogenetic tree. The evolutionary distances were computed using the Maximum Composite Likelihood method [44] and are in the units of the number of base substitutions per site. Evolutionary analyses were conducted in MEGA7 [45].

\section{References}

1. Zeigler, R.; Barclay, A. The Relevance of Rice. Rice 2008, 1, 3-10. [CrossRef] 
2. Savary, S.; Mila, A.; Willocquet, L.; Esker, P.D.; Carisse, O.; McRoberts, N. Risk factors for crop health under global change and agricultural shifts: A framework of analyses using rice in tropical and subtropical Asia as a model. Phytopathology 2011, 101, 696-709. [CrossRef] [PubMed]

3. Xiao, X.; Boles, S.; Liu, J.; Zhuang, D.; Frolking, S.; Li, C.; Salas, W.; Boore, B. Mapping paddy rice agriculture in southern China using multi-temporal MODIS images. Remote Sens. Environ. 2005, 95, 480-492. [CrossRef]

4. O'Shannassy, T.O. Greater Mekong Subregion (GMS): Context. Southeast Asian J. Trop Med. Public Health 2013, 44 (Suppl. 1), S1-S45.

5. Johnston, R.; Hoanh, C.T.; Lacombe, G.; Noble, A.; Smakhtin, V.; Suhardiman, D.; Pheng, K.S.; Sze, C.P. Rethinking agriculture in the Greater Mekong Subregion: How to sustainably meet food needs, enhance ecosystem services and cope with climate change. Iwmi Res. Rep. 2010. [CrossRef]

6. Ko, K.; Liu, Y.; Hou, M.; Babendreier, D.; Zhang, F.; Song, K. Evaluation for potential Trichogramma (Hymenoptera: Trichogrammatidae) strains for control of the striped stem borer (Lepidoptera: Crambidae) in the Greater Mekong Subregion. J. Econ. Entomol. 2014, 107, 955-963. [CrossRef]

7. Kaur, R.; Brar, K.S.; Singh, J.; Shenhmar, M. Large-scale evaluation of bio-intensive management for leaf folder and stem borer on basmati rice. J. Biol. Control 2007, 21, 255-259.

8. Otuka, A. Migration of rice planthoppers and their vectored re-emerging and novel rice viruses in East Asia. Front. Microbiol. 2013. [CrossRef] [PubMed]

9. Saleh, D.; Milazzo, J.; Adreit, H.; Fournier, E.; Tharreau, D. South-East Asia is the center of origin, diversity and dispersion of the rice blast fungus, Magnaporthe oryzae. New Phytol. 2014, 201, 1440-1456. [CrossRef] [PubMed]

10. Su, J.; Zhang, Z.; Wu, M.; Gao, C. Geographic susceptibility of Chilo suppressalis Walker (Lepidoptera: Crambidae), to chlorantraniliprole in China. Pest Manag. Sci. 2014, 70, 989-995. [CrossRef] [PubMed]

11. Lou, Y.G.; Zhang, G.R.; Zhang, W.Q.; Hu, Y.; Zhang, J. Reprint of: Biological control of rice insect pests in China. Biol. Control 2014, 68, 103-116. [CrossRef]

12. Cheng, X.; Chang, C.; Dai, S.M. Responses of striped stem borer, Chilo suppressalis (Lepidoptera: Pyralidae), from Taiwan to a range of insecticides. Pest Manag. Sci. 2010, 66, 762-766. [CrossRef] [PubMed]

13. Karthikeyan, K.; Jacob, S.; Purushothaman, S.M. Field evaluation of egg parasitoids, Trichogramma japonicum Ashmead and Trichogramma chilonis Ishii, against rice yellow stem borer and leaf folder. J. Biol Control. 2007, 21, 261-265.

14. Jin, J.Y.; Li, Z.Q.; Zhang, Y.N.; Liu, N.Y.; Dong, S.L. Different roles suggested by sex-biased expression and pheromone binding affinity among three pheromone binding proteins in the pink rice borer, Sesamia inferens (Walker) (Lepidoptera: Noctuidae). J. Insect Physiol. 2014, 66, 71-79. [CrossRef] [PubMed]

15. Lou, Y.; Hua, X.; Turlings, T.C.; Cheng, J.; Chen, X.; Ye, G. Differences in induced volatile emissions among rice varieties result in differential attraction and parasitism of Nilaparvata lugens eggs by the parasitoid Anagrus nilaparvatae in the field. J. Chem. Ecol. 2006, 32, 2375-2387. [CrossRef] [PubMed]

16. Zibaee, A.; Bandani, A.R.; Fazeli-Dinan, M.; Zibaee, I.; Sendi, J.J.; Maleki, F.A. A trypsin-like protease in rice green semi-looper, Naranga aenescens Moore (Lepidoptera: Noctuidae): Purification and characterization. Arch. Insect Biochem. Physiol. 2011, 78, 1-16. [CrossRef] [PubMed]

17. Deka, S.; Barthakur, S. Overview on current status of biotechnological interventions on yellow stem borer Scirpophaga incertulas (Lepidoptera: Crambidae) resistance in rice. Biotechnol. Adv. 2010, 28, 70-81. [CrossRef] [PubMed]

18. Gao, X.H.; Tian, J.H.; Chen, P. Population dynamics of Tryporyza incertulas (Walker) in Menghai, Yunnan from 2001-2011. J. Yunnan Univ. 2012, 34, 367-372. (In Chinese)

19. Desneux, N.; Decourtye, A.; Delpuech, J.M. The sublethal effects of pesticides on beneficial arthropods. Annu. Rev. Entomol. 2007, 52, 81-106. [CrossRef] [PubMed]

20. Landis, D.A.; Wratten, S.D.; Gurr, G.M. Habitat management to conserve natural enemies of arthropod pests in agriculture. Annu. Rev. Entomol. 2000, 45, 175-201. [CrossRef] [PubMed]

21. Sherif, M.R.; Hendawy, A.S.; El-Habashy, M.M. Utilization of Trichogramma evanescens (Ashmead) for controlling rice stem borer, Chilo Agamemnon Bles. in rice fields in Egypt. Egypt J. Biol. Pest Control 2008, 18, $11-16$.

22. Kaur, R.; Brar, K.S. Evaluation of different doses of Trichogramma species for the management of leaf folder and stem borer on Basmati rice. J. Biol. Control 2008, 22, 131-135. 
23. Shi, P.; Zhong, L.; Sandhu, H.S.; Ge, F.; Xu, X.; Chen, W. Population decrease of Scirpophaga incertulas Walker (Lepidoptera Pyralidae) under climate warming. Ecol. Evol. 2012, 2, 58-64. [CrossRef] [PubMed]

24. Hikjm, I.S. Seasonal parasitism by egg parasites of the yellow rice borer, Scirpophaga incertulas [Lepidoptera Pyralidae]. Entomophaga 1988, 33, 115-124. [CrossRef]

25. Chakraborty, K. Relative composition of egg parasitoid species of yellow stem borer, Scirpophaga incertulas Wlk. in paddy field at Uttar Dinajpur, West Bengal, India. Curr. Biot. 2012, 6, 42-52.

26. Samara, R.Y.; Monje, J.C.; Zebitz, C.P.W. Comparison of different European strains of Trichogramma aurosum (Hymenoptera: Trichogrammatidae) using fertility life tables. Biocontrol Sci. Technol. 2008, 18, 75-86. [CrossRef]

27. Guo, H.F.; Fang, J.C.; Xie, Y.F.; Du, Z.W. Egg parasitism of rice stem borers in regions with different rice stem borer occurring patterns. Chin. J. Biol. Control 2002, 18, 13-16. (In Chinese)

28. Riba, T.; Sarma, A.K. Efficacy of Trichogrmma japonicum Ashmead against yellow stem borer, Scirpophaga incertulas Walk on rice in Nagaland. J. Appl. Zool. Res. 2006, 17, 196-200.

29. Smith, S.M.; Hubbes, M. Strains of the egg parasitoid Trichogramma minutum Riley. 1. Biochemical and biological characterization. J. Appl. Entomol. Z. Angew. Entomol. 1986, 101, 223-239. [CrossRef]

30. Babendreier, D.; Kuske, S.; Bigler, F. Parasitism of non-target butterflies by Trichogramma brassicae (Hymenoptera: Trichogrammatidae) under semifield and field conditions. Biol. Control 2003, 26, 139-145. [CrossRef]

31. He, J.H. A method for investigation parasitism rate for yellow stem borer eggs. Plant Prot. 1966, 1, 38-40. (In Chinese)

32. ICM Team. Field survey on natural parasitism rate for yellow stem borer eggs in Wuhu City. J. Anhui Norm. Univ. (Nat. Sci.) 1974, 1, 50-54. (In Chinese)

33. Luo, L.Z.; Shepard, B.M. Predation and parasitism of yellow stem borer Scirpophaga incertulas (Walker) eggs influenced by rice plant density and growth stages. Acta Ecol. Sin. 1994, 37, 298-304. (In Chinese)

34. Sugiura, S.; Yamazaki, K. Caterpillar hair as a physical barrier against invertebrate predators. Behav. Ecol. 2014, 25, 975-983. [CrossRef]

35. Castellanos, I.; Barbosa, P.; Zuria, I.; Tammaru, T.; Christman, M.C. Contact with caterpillar hairs triggers predator-specific defensive responses. Behav. Ecol. 2011, 22, 1020-1025. [CrossRef]

36. Gentry, G.L.; Dyer, L.A. On the conditional nature of neotropical caterpillar defenses against their natural enemies. Ecology 2002, 83, 3108-3119. [CrossRef]

37. Stireman, J.O.; Singer, M.S. Determinants of parasitoid-host associations: Insights from a natural tachinid-Lepidopteran community. Ecology 2003, 84, 296-310. [CrossRef]

38. Song, K.; Tang, R.; Babendreier, D.; Zhang, F.; Hou, M.L. Institute of Plant Protection, Beijing, China. Unpublished data. 2017.

39. Nicol, C.M.Y.; Mackauer, M. The scaling of body size and mass in a host-parasitoid association: Influence of host species and stage. Entomol. Exp. Appl. 1999, 90, 83-92. [CrossRef]

40. King, B.H. Host-size-dependent sex ratios among parasitoid wasps: Does host growth matter? Oecologia 1989, 78, 420-426. [CrossRef]

41. Kazmer, D.J.; Luck, R.F. Field tests of the size-fitness hypothesis in the egg parasitoid Trichogramma pretiosum. Ecology 1995, 76, 412-425. [CrossRef]

42. Saitou, N.; Nei, M. The neighbor-joining method: A new method for reconstructing phylogenetic trees. Molecular Biology and Evolution 1987, 4, 406-425. [PubMed]

43. Felsenstein, J. Confidence limits on phylogenies: An approach using the bootstrap. Evolution 1985, 39, 783-791. [CrossRef]

44. Tamura, K.; Nei, M.; Kumar, S. Prospects for inferring very large phylogenies by using the neighbor-joining method. Proc. Natl. Acad. Sci. USA 2004, 101, 11030-11035. [CrossRef] [PubMed]

45. Kumar, S.; Stecher, G.; Tamura, K. MEGA7: Molecular Evolutionary Genetics Analysis version 7.0 for bigger datasets. Mol. Biol. Evol. 2015. [CrossRef] [PubMed]

(C) 2017 by the authors; licensee MDPI, Basel, Switzerland. This article is an open access article distributed under the terms and conditions of the Creative Commons Attribution (CC BY) license (http:/ / creativecommons.org/licenses/by/4.0/). 